\title{
Time Based Success in Creation of Initiative Arterio- Venous Fistula for Patients with Chronic Renal Failure need Haemodialysis
}

\author{
Muayyad M. Almudhafer * \\ *College of Medicine / University of Basra / Iraq
}

\begin{abstract}
:
Background : Patients with chronic kidney disease need permanent vascular access for hemodialysis and the best choice is by surgically created arterio-venous fistula. Artificial AVF is a challenging surgery because it carries a high failure rate with increasing morbidity and mortality.

Objectives : to highlight the importance of time factor (the time interval between the establishment of CKD to the time of creation of $\mathrm{AVF}$ ) as a predictor factor affecting the outcome of surgery.

Methodology : a retrospective descriptive analytic study of 216 patients ( 124 male and 92 female) all with chronic kidney disease underwent surgical creation of AVF for hemodialysis in the vascular unit at Sader teaching hospital/Basra, south of Iraq from $1^{\text {st }}$ of January 2010 to $30^{\text {th }}$ of June 2012.

Results : the overall success rate was $55.55 \%$ and the failure rate was $44.45 \%$, the causes of failure in sequence were inadequate vein $(51 \%)$, technical difficulties $(16.6 \%)$, fistula thrombosis (11.6\%), bleeding (9.4\%), false aneurysm (7.3\%) and distal ischemia (4.1\%), the patients followed up after 24 hours, 1 week, 1 month and 6 months.

Conclusion : the outcome of the surgery is affected by the time interval between the establishment of diagnosis of CKD and the time of surgical creation of AVF, the success rate is decreased with increasing time interval and become abrupt after 6 months, while the failure rate is increasing smoothly with increasing time interval with peak increase being after 6 months.
\end{abstract}




\section{Introduction:}

Functional long-term vascular access is essential for efficient hemodialysis for patients with end stage renal disease (ESRD). Thus, planning for vascular access is important for a smooth start to hemodialysis (HD). Vascular access may be created at least 3 months before the estimated dialysis start date (1), allowing time for the fistula to mature, and avoiding the need for temporary access and attendant risks such as trauma, septicemia, venous stenosis and thrombosis (18). The three principal forms of chronic vascular access for hemodialysis are native arteriovenous fistulas (native AVFs), arteriovenous shunts using graft material ( AV graft ), and tunneled double- lumen catheters. The native AVF is preferred for long term hemodialysis vascular access since it has the best long term primary patency rate, requires the fewest interventions of any other type of access, and most importantly, AVFs are associated with the lowest incidence of morbidity and mortality (2-6) Many studies were made to analyze factors that could affect the patency of AVFs, some of these studies showed that the outcome of creation AVFs is affected by types of vascular anastomosis, age more than 46years, the time of $1^{\text {st }}$ canulation, and female gender with diabetes $\quad(7,8)$ Other studies demonstrate that other major co morbidity supposed to be risk factors could not affect the patency of AVFs like diabetes, hypertension, glomerulonephritis uropathy, lupus and smoking (7).

Our study try to analyze the effect of time factor as a risk predictor for the

outcome of AVFs. We mean by the time factor is the time period that started from the establishment of the diagnosis of chronic kidney disease (CKD) till the time of surgical creation of AVFs for haemodialysis.

\section{Methodology :}

Study Design : it is a retrospective descriptive-analytic study in a single vascular center based on patients with CKD referred for surgical creation of AVFs for haemodialysis.

Patients Selection : a two hundreds sixteen patients referred from nephrology units in Basrah, Meisan and Naseriya ( south of Iraq ) in a period from $1^{\text {st }}$ of January 2010 to $30^{\text {th }}$ of June 2012 all included in a program of creation of artificial AVFs for haemodialysis.

An important informations are obtained including demographic data, hospital stay, associated morbidities ( hypertension, obesity and smoking), which limb and the site of limb used for creation of AVFs, the time period between the establishment of the diagnosis of chronic renal failure till the time of creation of

AVFs (taken as a predictor factor for outcome of surgery), the technique of surgery, assessment of outcome immediately and after 24 hours, 1 week, 1 month and 6months by face to face visits and by direct contact with the nephrologists that take the responsibility of the patients. 


\section{Email:utjmed@utq.edu.iq}

No specific preparations done preoperatively apart from blood test for $\mathrm{Hb} \%$, RBS, B.Urea, S.creatinin, and viral markers for $\mathrm{HBV}$ and $\mathrm{HCV}$, with advice to avoid any venous injection or venisection around the cubital fossa. Venous Doppler mapping is not done because it is not available in our center.

All patients have their $1^{\text {st }}$ attempt for surgical creation of AVF ( initiative AVFs ), many patients are excluded from this study including patients died or lost for follow up during the period of the study, patients with major co morbidities and risk factors known to be badly affect the health status of the blood vessels like diabetes mellitus, SLE, advanced atherosclerosis and small sized arteries.

All failed procedures, the causes of failure and complications were recorded, the mode of complications were analyzed according to the time of presentation.

Statistical analysis : the data collected and entered into SPSS software version 17.0 ,
Web Site: https://imed.utq.edu.iq

t-test and Chi-Squares test were used to analyzed the results with $95 \%$ level of significance.

Surgical technique : in all patients an initiative AVFs are created in the upper extremities (dominant and non dominant arms) around the elbow between the brachial artery and the most suitable vein ( antecubital, cephalic and basilic veins), the veins are assessed preoperatively by clinical examination (no ultrasonic device or other tools are adopted) and intraoperatively by direct examination regarding the size, length, consistency and lumen patency. the brachial artery and the selected vein are mobilized and freed for adequate length and an incisions of 4-6mm length are made and the fistulae are created by side-side and end-side anastomosis using 6-0 and 7-0 polypropylene sutures. At the completion of surgery the fistulae are assessed by direct palpation for machinery thrill and auscultated for bruit then assessed after 24 hours, 1 week, 1 month and 6months by clinical examination and hand hold Doppler device. 


\section{Results :}

Table ( 1 ). Demography and Hospital Stay. Tow hundreds sixteen patients (124 males and 92 females, with male : female Ratio of $1: 0.74$ ), the average age is 52years and average hospital stay was 37 hours. All of them have renal failure that necessitated creation of AV fistulas Table (1).

\begin{tabular}{|c|c|c|c|c|}
\hline \multirow[t]{2}{*}{ Parameter } & \multicolumn{2}{|c|}{ Distribution } & \multirow[t]{2}{*}{ Statistical test } & \multirow[t]{2}{*}{$P$ value } \\
\hline & Male & Female & & \\
\hline Gender & $124(57.4 \%)$ & 92 (42.6\%) & NA & - \\
\hline $\begin{array}{l}\text { Age (mean +/- } \\
\text { SD) }\end{array}$ & 52.42 years & 52.00 years & $\begin{array}{l}\text { Independent } \\
\text { sample t-test } \\
\text { value }=0.197\end{array}$ & 0.844 \\
\hline Hospital stay & 37.94 weeks & 37.57 weeks & $\begin{array}{l}\text { Independent } \\
\text { sample t-test } \\
\text { value }=0.157\end{array}$ & 0.370 \\
\hline
\end{tabular}

Table ( 2 ) Co - Morbidities. The basic three co morbidities in this study were hypertension in 100 patients (46.3\%), obesity in 28 patients (13\%) and smoking in 16 patients (7.4\%), these co-morbidities occurred in 117 patients (54\%) and some of the patients have more than one co-morbidity. All patients with other risk factors are excluded from the study, table (2).

\begin{tabular}{|c|c|c|c|c|}
\hline \multirow{2}{*}{ Risk } & \multicolumn{2}{|c|}{ Distribution } & Statistical test & \multirow{2}{*}{ P value } \\
\cline { 2 - 5 } & Male & Female & & \\
\hline Hypertension & 64 & 36 & 3.31 & 0.069 \\
\hline Obesity & 1 & 27 & NA & NA \\
\hline Smoking & 8 & 8 & NA & NA \\
\hline
\end{tabular}


Table ( 3 ). The Outcome according to Gender. The outcome of the procedures was analyzed after 24 hours, 1 week, 1 month and after 6 months. The results were classified into 2 main groups, the failure group and successful group table (3). The group of failed procedures were sub classified according to the causes of failure into inadequate vein, fistula thrombosis, technical difficulties, persistent or serious post operative bleeding, development of false aneurysms, and limb threatening ischemia table (4). After 6months of follow up, 120 patients ( $55.55 \%$ ) found to have successful creation of AVFs, 73 patients ( $60.8 \%$ ) were male and 47 patients ( $39.2 \%$ ) were female. There were 96 patients $(44.45 \%)$ with failed procedures, 51 patients $(53.1 \%)$ male and 45 patients $(46.9 \%)$ were female table (3).

\begin{tabular}{|c|c|c|c|c|}
\hline & \multicolumn{2}{|c|}{ Fate } & Statistical test & \multirow{2}{*}{ P value } \\
\cline { 2 - 4 } & Failure & Success & & \\
\hline Male & 51 & 73 & Chi Squared & 0.355 \\
Female & 45 & 47 & test & \\
\hline Total & 96 & $120(55.55 \%)$ & 1.296 & \\
& $(44.45 \%)$ & & & \\
\hline
\end{tabular}

Table ( 4 ). The Causes of Failure

\begin{tabular}{|c|c|c|c|c|c|c|}
\hline \multicolumn{7}{|c|}{ The Causes of Failure } \\
\hline $\begin{array}{c}\text { Inadequate } \\
\text { vein }\end{array}$ & $\begin{array}{c}\text { Technical } \\
\text { difficulties }\end{array}$ & & & & $\begin{array}{c}\text { Distal } \\
\text { Ischemia }\end{array}$ \\
\hline Male & 28 & 10 & 7 & 1 & 4 & 1 \\
\hline Female & 21 & 6 & 4 & 8 & 3 & 3 \\
\hline $\begin{array}{c}\text { Total } \\
\%\end{array}$ & 49 & 16 & 11 & 9 & 7 & 4 \\
\hline
\end{tabular}




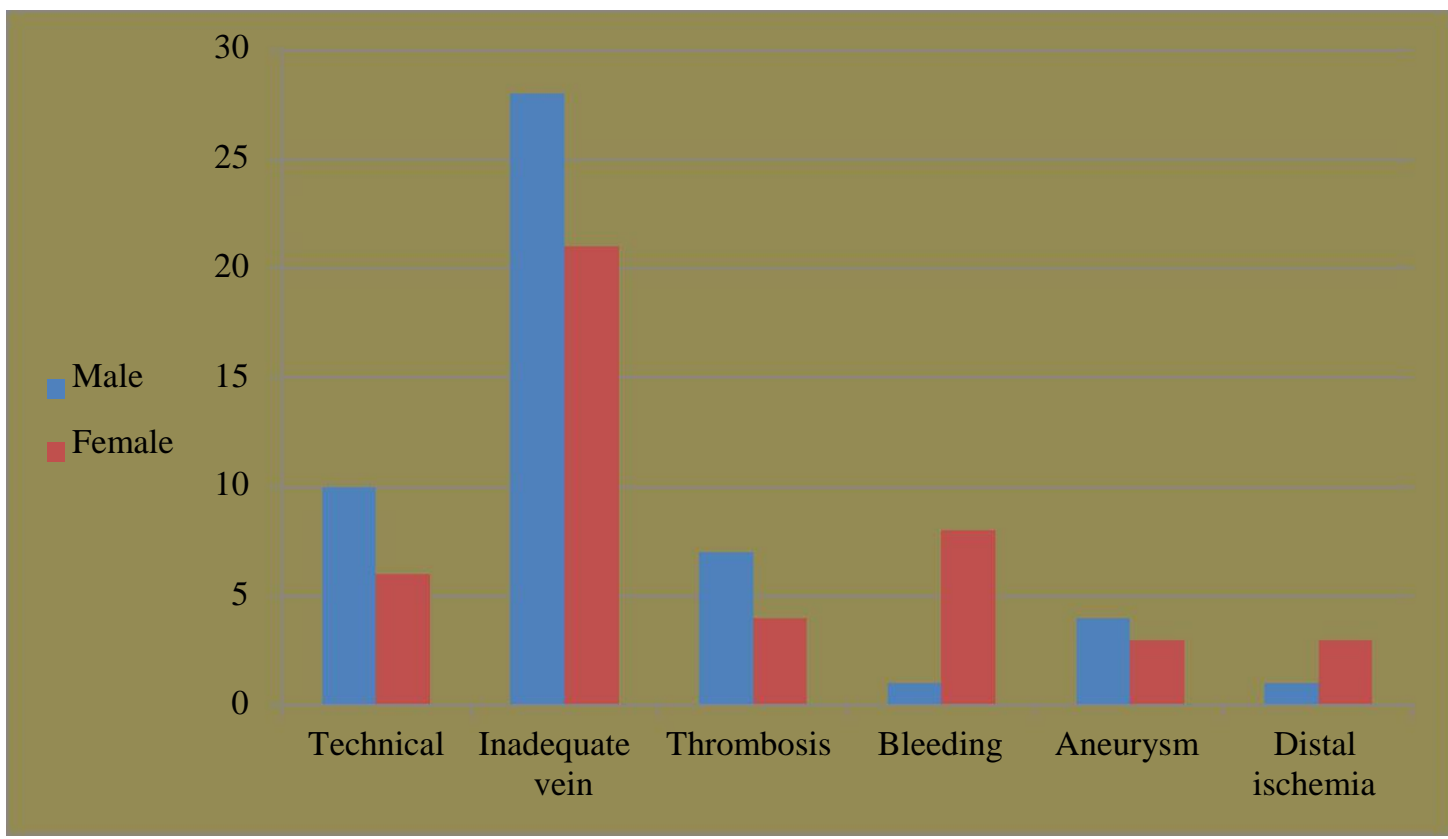

Figure ( 1 ). The causes of failure were mostly due to inadequate vein in 49 patients (51\%), technical difficulties in 16 patients $(16.6 \%)$, and less common due to fistula thrombosis in 11 patients $(11.6 \%)$, bleeding in 9 patients $(9.4 \%)$, false aneurysm in 7 patients $(7.3 \%)$ and distal ischemia in 4 patients (4.1\%), table (4). The frequency of complications according to gender is demonstrated in figure (1).

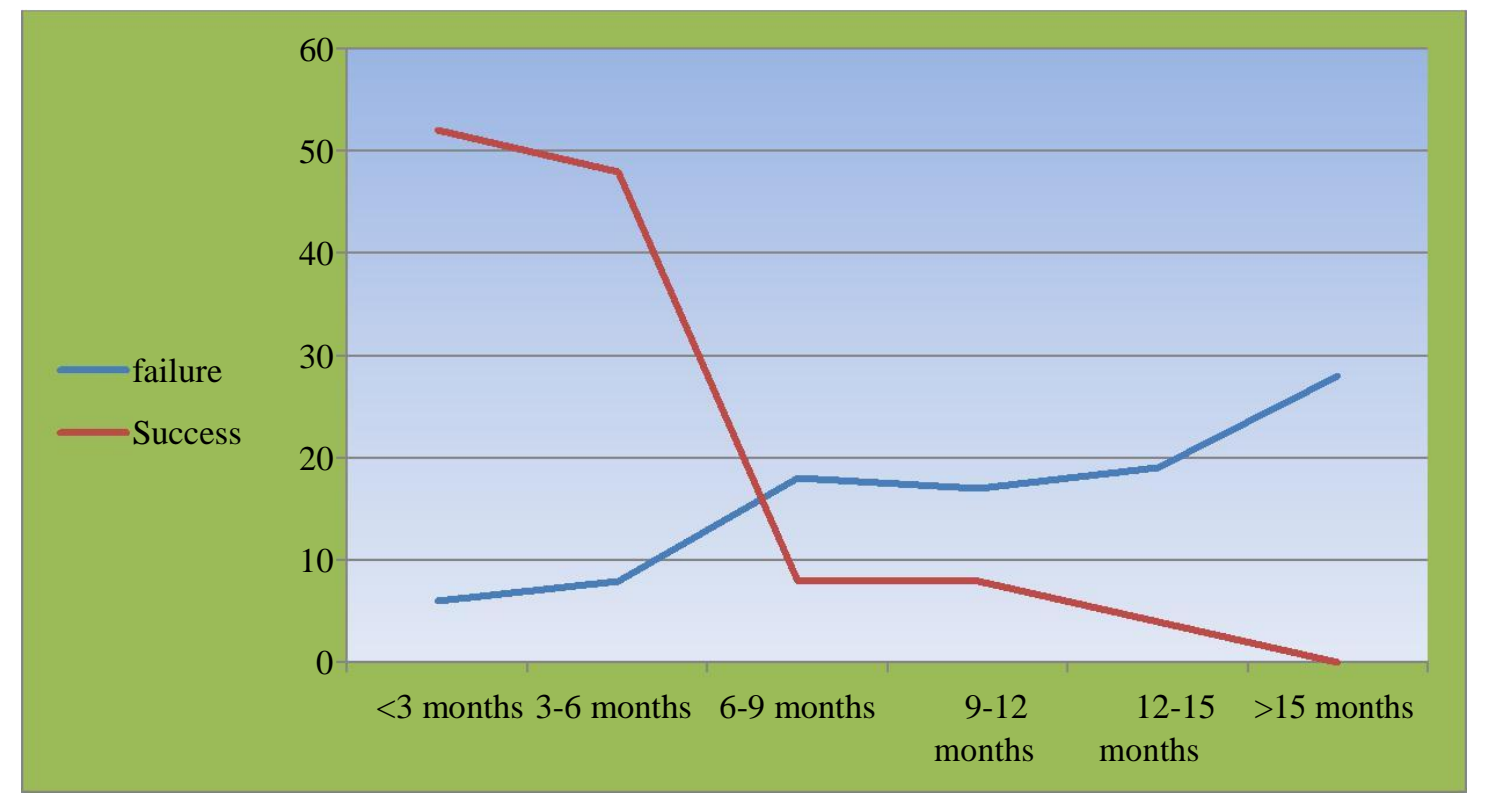

\section{Figure ( 2 ).}

According to the time interval between the establishment of the diagnosis of chronic kidney disease and the time of surgical creation of the fistulas the number of patients with successful procedures are decreasing with time with a peak decline after 6 months interval, on the reverse there is a smooth increase in the number of patients got failure procedures due to increasing in the time interval with abrupt increase in number after 6 months and the highest number of patients being operated upon after 15 months duration, figure (2). 


\section{Email:utjmed@utq.edu.iq}

\section{Discussion :}

Once arteriovenous fistula is created, it must develop to the point that it is usable. The vascular access dysfunction is one of the most important causes of morbidity in hemodialysis patients ${ }^{(9)}$. Some of the co-morbid factors found to be affecting badly the outcome of AVF creation like small sized arteries, diabetic patients, and fistulas that created in the lower part of the forearm $(6,7,8,16)$.

All patients are referred from nephrology centers in three provinces (Basrah, Meisan and Naseriya, south or Iraq), Surgeries were attempted under local anesthesia and the surgical technique was by releasing of the most suitable vein and the brachial artery with creation of $4-6 \mathrm{~mm}$ AVF by side to side and end to side anastomosis using 6-0 and 7-0 polypropylene sutures, this surgical technique is preferred by many authors with big experience because it is easier way with better outcome $(5,12$,$) . After$ finishing the surgery the incision is closed by closing the skin only and dressed with crepe bandage and the arm kept elevated above the body level which is partially flexed at elbow joint to prevent subsequent oedema and tension on anastomotic site.

The average hospital stay is about 37days table (1), it is equal in men and women, because we kept the patients for at least 24hours following surgery for

clinical observation if any immediate or early complications develop and to assess the outcome of the fistulas clinically and by hand-hold Doppler
Web Site: https://imed.utq.edu.iq

after 24hours. Some patients may kept for longer time when immediate or early complications develop that mandate intervention.

There are 117 patients $(54 \%)$ in this series with one or more of the three co-morbidities mentioned in this study (hypertension 46.3\%, smocking $13 \%$ and obesity

with $\mathrm{BMI}>25$ and $<35 \mathrm{Kg} / \mathrm{m}^{2} 7.4 \%$ ) table(2), and in many studies they found that these factors are not predictor for failure of creation of AVF $(7,14,15,19)$ , for that reason those patient were not excluded from the study.

The primary AVF failure rate is approximately $9-50 \%(11,12,13)$, in our study the success rate is $55.55 \%$ which is comparable with previous studies $(6,17,18)$. There is no

great difference in failure rate between gender with 51 male and 46 female with a male : female ratio of $1: 0.9$ which is statically not significant, on the other hand AVF success rate is more in male than female patients with 73 male and 47 female patients and a male : female ratio of $1: 0.64$ table(3), So we agree with others that female gender is not a predictor factor for AVF failure $(6,16,17)$.

Evaluation of Fistula 4-6 weeks after creation should be considered mandatory (14). the clinical manifestations of early fistula failure are failure to develop adequately to permit repetitive canulation for dialysis, inadequate flow to support dialysis, and thrombosis ${ }^{(8)}$. The primary failure of native fistulas occur as a result of either thrombosis with in the $1^{\text {st }}$ several weeks following surgical creation ( early 


\section{Email:utjmed@utq.edu.iq}

thrombosis ), or inadequate maturation of the veins ${ }^{(10)}$. In our study the failure rate was $44.45 \%$ table(3), and the commonest cause of failure was inadequate veins that have no enough size, length or lumen to anatomized with the artery to create fistula in $51 \%$ of all failure procedures while the other causes are less frequent including technical difficulties in $16.6 \%$, fistula thrombosis in $11.6 \%$, uncontrolled bleeding in $9.4 \%$, false aneurysm in $7.3 \%$, and distal ischemia in $4.1 \%$ table(4) and figure(1).

We found that time factor play important role in the outcome of the AVFs, we mean by the time factor in this study is the time period that extend between the establishment of the diagnosis of chronic kidney disease (CKD), till the time of surgery to create AVF. With analyzing the data shown in figure (2), the diagram is clearly demonstrate that the success rate is abruptly decline when the surgery adopted after 6 months from the diagnosis of $\mathrm{CKD}$, while the failure rate is smoothly increased with time with a peak of increase being started after 6 months. In all patients we found that the surgical technical difficulties were in the venous rather than the arterial side and we found that the morphological changes are much more on the venous system, and this is may be attributed in one way to the adoption of repeated puncturing of the veins around the cubital fossa for venisection or as a venous access for fluid and drug administration, and in another way to the established histopathological changes that affecting the smooth muscle cells in the medial layer and the changes that affecting the intima.
Web Site: https://imed.utq.edu.iq

\section{Conclusion :}

Chronic kidney disease is a disabling condition, mandate surgical creation of AVFs for hemodialysis as a bridge for renal transplantation when it is possible, or as a principal management for those who are not candidate for renal transplantation for one reason or another. Surgically created AVF is a major contributor to the hospitalization of hemodialysis patients and their overall morbidity and mortality, AVF also impose a substantial financial burden, accruing more than one billion dollars per year in healthcare costs excerpts from the US Renal Data System 2009 Annual Data Report. We found in this study that the time factor ( the time period from establishment of the diagnosis of CKD to the time of surgical creation of AVF ), play an important role in deciding the outcome of surgery, and accordingly we advice to refer patients with CKD once diagnosis is established or at least with in 6 months from the onset of the clinical and biochemical features of CKD to achieve better outcome and reduce risk of fistula failure and morbidity and mortality.

\section{References :}

1. Mansfield PE, Hohn DC, Fornage $\mathrm{BD}$, et al. Complications and failure of subclavian-vein catheterization. New Engl J Med 1994; 331: 1735-38.

2. Feldman HI, Kobrin S, Wasserstein A. hemodialysis vascular access morbidity. J Am Soc Nephrol 1996; 7:523.

3. Ascher E, Gade P, Hingorani A, et al. Changes in the practice of angio access surgery: impact of dialysis outcome and quality initiative 


\section{Email:utjmed@utq.edu.iq}

recommendations. J Vas Surg 2000; 31:84.

4. Allon M, Robbin ML. increasing arteriovenous fistulas in hemodialysis patients: problems and solutions. Kidney Int 2002; 62: 1109-24.

5. Dexon BS, Novak L, Fangman J, hemodialysis vascular access survival: upper arm native arteriovenous fistula. Am J Kidney Dis 2002; 39:92.

6. Anel RL, Yevzlin AS, Ivanovich P. Vascular access and patient outcome in hemodialysis: questions answered in recent literature. Artif Organs 2003; 27:237.

7. Wang W, Murphy B, Yilmaz S, Tonelli M, Macrac J, Manns BJ. Co morbidities do not influence primary fistula success in incidental hemodialysis patient. J Vas Access 2007; 8:275-280.

8. Tadenusz M, Waldemar K. Estimation of predictive factors affecting patency of dialysis after arteriovenous fistulae. ( medline).

9. Woods JD, Port FK. The impact of vascular access for hemodialysis on patient morbidity and mortality. Nephrol Dial Transplant 1997; 12 : 657-9.

10. Asif A, Roy-Chandhury P, Beathard GA. Early arteriovenous fistula failure: A logical proposal for when and how to intervene. Clin J Am Soc Nephrol 2006; 1: 332-9.

11. Asif A, Cherla G, Merill D, Cipleu CD, Briones P, Pennell P. Conversion of tunneled hemodialysis catheter consigned patients to arteriovenous fistula. Kidney Int 2005; 67 : 2399407.

12. Miller PE, Tolwani A, Luscy CP, Deierhoi MH, Bailey R, Redden, et al. predictors of adequacy of
Web Site: https://imed.utq.edu.iq

arteriovenous fistulas in hemodialysis patients. Kidney Int 1999 ; 56 : 275-89. 13. Beathard GA, Arnold P, Jackson J, Litchfield T. Aggressive treatment of early fistula failure. Kidney Int 2003 ; 64 : 1487-94.

14. Roy-Chaudhury P, Kelly BS, Zhang J, Narayana A, Desai P, Melham M, et al. Prevention of P.O. clotting of AV cimino fistulas with acetylsalicylic acid : Results of a prospective double blind study. Klin wochenschr 1974 ;

$52: 348-9$.

15. Carrie A. Schinstok, Robert C. Albright, Karl A. Nath. Outcome of arteriovenous fistula creation after the fistula first initiative. Clin J Am Soc Nephrol 2011 August; 6(8) : 19962002.

16. Feldman HI, Joffe M, Rosas SE, Burns JE, Knauss J, Brayman K. Predictors of successful arteriovenous fistula maturation. Am J Kidney dis; 42 : 1000-1012, 2003.

17. Huijbergts HT, Bots ML, Wittens CH, Schrama YC, Moll FL, Blankestijn PT. Hemodialysis arteriovenous fistula patency revisited : Results of prospective multicenter initiative. Clin J Am Soc Nephrol 3: 714-719, 2008.

18. Oliver MJ, Rothwell DM, Fung K, et al. Late creation of vascular access for hemodialysis and increased risk of sepsis. J Am Soc Nephrol 2004;15:936-42.

19. Rooijens PP, Tordoir JH, Stejinen T, Burgmans JP, Smet de AA, et al. Radio cephalic wrist arteriovenous fistula for hemodialysis : meta-analysis indicates a high primary failure rate. Eur J Vasc Endovasc surg 2004;28:583-9. 
20. Vassalotti JA, Falk A, Cohl ED, Uribarri J, Teodorescu V. obese and non-obese hemodialysis patients have a similar prevalence of functioning arteriovenous fistula using preoperative vein mapping. Clin Nephrol 2002;58:211-14.
21. Chan MR, Young HN, Becker YT, Yevzlin AS. Obesity as a predictor of vascular access outcome: Analysis of the USRDS DMMS Wave II study. Semin Dial 2008;21:274-9. 22. 
Web Site: https://imed.utq.edu.iq Email:utjmed@utq.edu.iq

\section{الهية عامل الوقت في نجاح عملية صناعة ناسور شرياني وريدي عضدي اولية لمرضى الفشل الكلوي المزمن المحتاجين للايلزة الدموية فئية}

مؤيد محمد المظفر

الخلاصة :

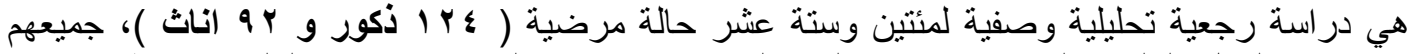

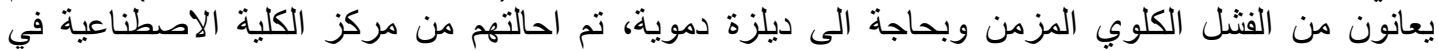

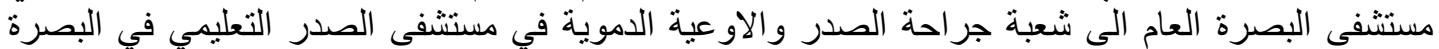

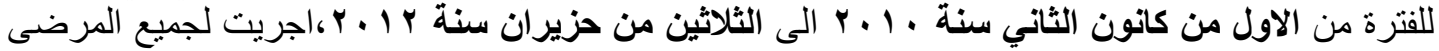

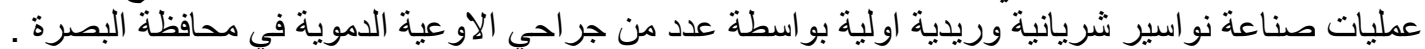

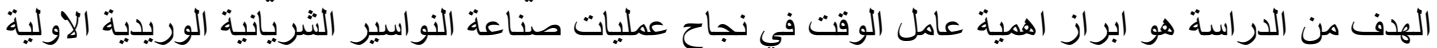

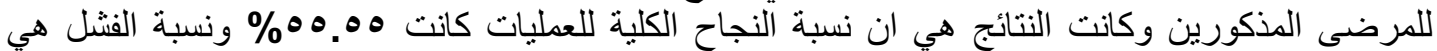

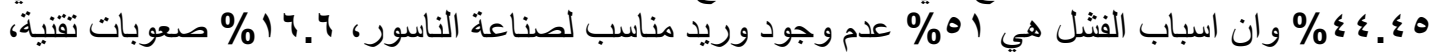

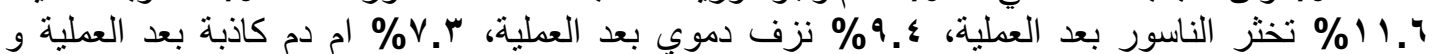

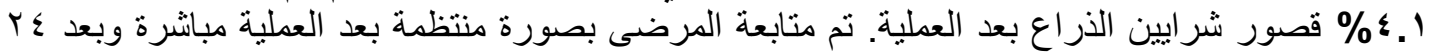

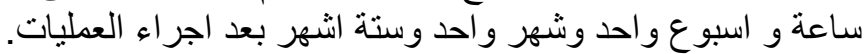

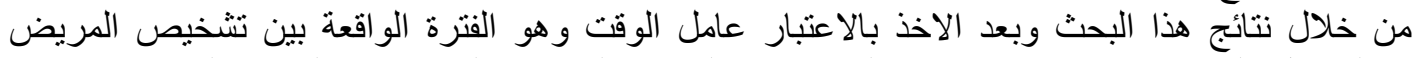

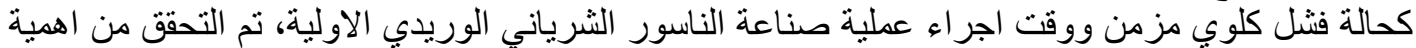

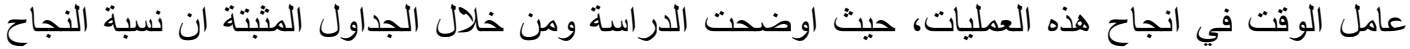

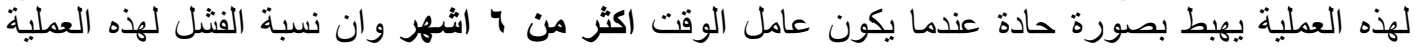

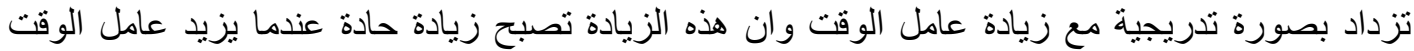
على 1 اشهر. 